\title{
Effects of Quadriceps Strengthening Exercise on Quadriceps Muscle Strength and Its Relation to Lower Extremity Lean Mass
}

\author{
Istingadah Desiana, Marina Annette Moeliono, Tertianto Prabowo
}

Department of Physical Medicine and Rehabilitation, Faculty of Medicine, Universitas Padjadjaran-Dr. Hasan Sadikin General Hospital, Bandung

\begin{abstract}
Objective: To discover whether quadriceps resistance exercise could increase quadriceps strength as well as its relation to lower extremity lean mass.

Methods: This study was a pre- and post- experimental study in which 36 participants with knee OA grade 2 and 3 were recruited. Assesment of leg lean mass and quadriceps strength was taken before and after intervention. Participants practiced quadriceps isotonic resistance exercise 3 times a week for 8 weeks. This study was conducted in Dr. Hasan Sadikin General Hospital, Bandung from September 2014 to February 2015.
\end{abstract}

Results: After the intervention, an increase in quadriceps strength was seen but not in the lower extremity lean mass. Statistical analysis showed that there was no correlation between lower extremity lean mass and quadriceps strength.

$\begin{array}{ll}\text { Received: } & \text { Conclusions: Quadriceps strength is found to increase after intervention. No } \\ \text { May 5, 2017 } & \text { increan }\end{array}$ increase is found in the lower extremity lean mass.

Revised:

August 8, $2017 \quad$ Keywords: Osteoarthritis, leg lean mass, quadriceps strength, quadriceps Accepted:

September 4, 2017 pISSN: 2302-1381; eISSN: 2338-4506; http://doi.org/10.15850/ijihs.v5n2.1010 IJIHS. 2017;5(2):84-8

\section{Introduction}

Osteoarthritis or OA is a non-communicable disease with a high prevalence in Indonesia, i.e. $30.3 \%$, with $65.4 \%$ cases found in older patients who are above 75 years old. ${ }^{1}$ Knee osteoarthritis is a complex disease marked by changes of all parts of the joint. These changes are thought to be triggered by biochemical and biomechanical factors, most importanly is obesity and quadriceps muscle weakness. ${ }^{2}$

Muscle strength is found to be decreasing in elderly with smaller cross-sectional area which then affects the quadriceps muscle strength. ${ }^{3,4}$ Central obesity measurement, such as body mass index, waist circumference, and waist-hip ration, has a significant correlation with knee OA (KOA) and also known as a risk for KOA. However, this kind of measurement

\footnotetext{
Correspondence:

Istingadah Desiana, Department of Physical Medicine and Rehabilitation, Faculty of Medicine, Universitas Padjadjaran-Dr. Hasan Sadikin General Hospital Jl. Pasteur No. 38, Bandung, Indonesia e-mail: istingadah@gmail.com
}

has some weaknesses due to the fact that it only measure general fat and cannot differentiate between fat mass and lean mass. ${ }^{5}$

Body composition consists of lean mass, fat mass, and bone mass. Lean mass is furthermore divided into upper extremity, trunk, and lower extremity lean mass which can be measured using Bioelectrical Impedance Analysis (BIA). ${ }^{6}$

Conroy et al. ${ }^{3}$ found that the lower extremity lean mass (LELM) in women with KOA aged 45-69 years old is lower when compared to control group. This study presents a hypothesis that decreased LELM plays an important role in the pathogenesis of $\mathrm{KOA}^{3}$ Blumenfeld et $a l^{5}$ found that LELM is an strong predictor for defining Kelgreen-Lawrence score and medial osteophyte in KOA. Knee OA risk is increasing in women after menopause due to hormonal fluctuations, sedentary lifestyle, and fat-rich food consumption that contribute to weight gain. $^{7}$

Weight loss in patients with knee OA should be managed through an exercise regimen in order to restore or increase the muscle mass. 
Henriksen et al.$^{8}$ found that LELM increase and knee flexion-extension muscle strength with the use of low-energy diet are not found to be significantly correlated. This method can lead to muscle tissue loss and reduced lower limb muscle strength.

Increased LELM is also found to contribute to increased muscle strength in seven young individuals. Progressive resistance exercises can help increasing muscle mass. In addition, muscle strengthening exercises three times per week improve muscle strength and value of fat-free mass compared to the strengthening exercises only once per week. ${ }^{9,10}$

The aim of this study was to assess whether quadriceps strengthening exercise correlates with quadriceps strength and LELM.

\section{Methods}

Participants included in the study were patients visited Department of Physical Medicine and Rehabilitation of Dr. Hasan Sadikin General Hospital, Bandung. Thirty-six women were selected through consecutive sampling. The inclusion criteria were aged 4070 years old, Kelgreen-Lawrence grade II or III knee OA in subacute or chronic phase, walked without any assistive device, and understood verbal, written, and gesture instructions. The confirmation of knee OA diagnosis using the AP/lateral knee radiographic examination was made and the results from all participants were read by a same person. The exclusion criteria were history of having stroke or other nerve system dysfunctions, knee deformity (such as knee valgus-varus deformity, recurvatum), history of knee trauma (fracture, ligament or meniscus rupture), or any other knee surgery, did high intensity sport regularly or joined other muscle strengthening exercise in the last six months. The attendance was recorded in each training session to monitor compliance. All participants provided written informed consent, and this study was approved by the Ethical Comittee of Dr. Hasan Sadikin General Hospital, Bandung.

Lower extremity lean mass was measured using bioelectrical impedance analysis (Tanita MC-180, Japan). Data were collected two days prior to the first exercise and the participants were asked not to do any exercise 24-hours before, not consuming any alcohol 48-hours before, and not consuming any diuretics 7 days before. The participants were asked to empty the bladder before examination. During the measurement, the patient were forbidden to use any metal accesories and socks. If the partcipant skipped one exercise, she would be excluded from the study.

The measurement of the quadriceps muscle exercise strength using a push-pull handheld dynamometer was performed during the first exercise and after the whole intervention was completed. The measurement was peformed using 1 Repetition Maximum(RM) in which the participants performed the movement against the tester three times and the average result was calculated. The tester here was the same for all participants both before and after the intervention.

The intervention was implemented for eight weeks, three times a week in PMR gymansium using quadriceps bench exercise (Fig. 1). The intensity of quadriceps strengthening exercise was $60 \%$ of 1 Repetition Maximum (RM). In the study, $1 \mathrm{RM}$ was measured by extending the knee three times and $1 \mathrm{RM}$ score was recorded every week. The $60 \%$ intensity of the exercise was then fitted for the next week exercise. The exercise repetition was 10-15 times, with 1-2 seconds of resting. Before the exercise, a warming-up exercise was peformed for 10 minutes dan a stretching exercise was performed for 5 minutes. After the exercise, the participants performed the cooling down movements.

Data were analysed using the Shapiro Wilks for normality of distribution. To compare the relationship between two variables before and after exercise between two average data a paired t test was used. Data were processed by StatSoft program version 3.5 and Minitab 16 for windows with a statistical significance test results determined based on $\mathrm{p} \leq 0.05$ value.

\section{Results}

Thirty six participants were recruited in this study. Only females participated in this study. The mean age of subjects of this study was $57.26(\mathrm{SD}+7.45)$ years with an average body mass index (BMI) of 27.89 (SD+3.52). The mean height was $149.8(\mathrm{SD}+4.65) \mathrm{cm}$ (Table).

The means of quadriceps muscle strength before the intervention were $12.72 \mathrm{~kg}$ and $13.15 \mathrm{~kg}$ for the left and right sides, respectively. After the intervention, the quadriceps muscle strength means were $16.43 \mathrm{~kg}$ for left side and $16.45 \mathrm{~kg}$ for right side. This study found increased quadriceps muscle strength, i.e. $3.125 \mathrm{~kg}$ for left LE and $2.5 \mathrm{~kg}$ for right LE. This study found a significant difference before and after intervention. 


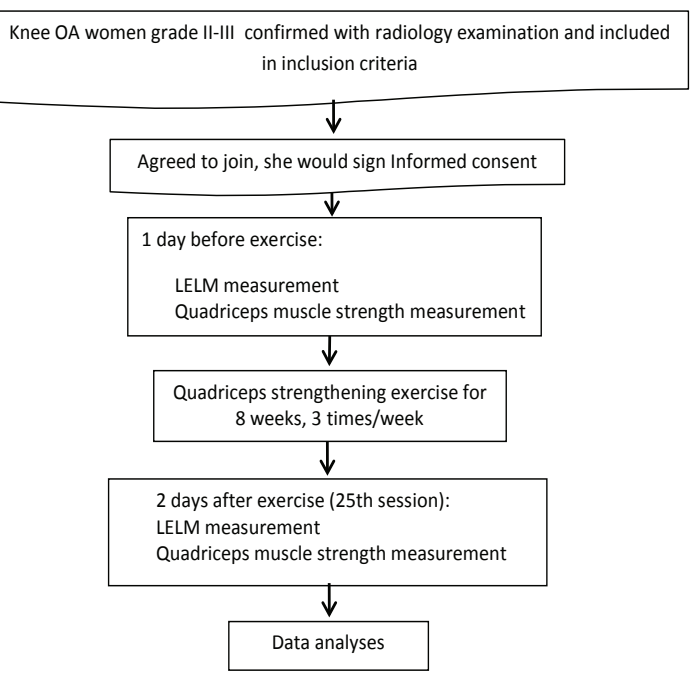

Fig. Intervention Flowchart

The means of the lower extremity lean mass before intervention were $39.47 \%$ and $39.37 \%$ for the left and right sides, respectively. After the intervention, the LELM means became $39.23 \%$ for the left side and $39.09 \%$ for the right side. No significant difference was seen between before and after the intervention ( $p=0.095$ and $p=0.67$ for left and right sides).

The quadriceps muscle difference between before and after intervention were $3.125 \mathrm{~kg}$ for the left side and $2.5 \mathrm{~kg}$ for the right side while the LELM difference were -0.025 and 0.053 for the left and right sides, respectively. The correlation of the LELM and quadriceps muscle strength before and after intervention was also not found based on the result of the paired t-test statistical analysis ( $p>0.05)$.

\section{Discussion}

The participants of this study were women with knee OA grade II-III aged less than 70 years old and met the inclusion criteria. They were given 24 times strengthening quadriceps exercise over eight weeks. This study aimed to assess whether the quadriceps strengthening exercise could increase LELM and whether it correlated to the quadriceps muscle strength.

The participant's mean age in this study was $57.26+7.45$ years. A study also found that the knee OA prevalence in the age group of more than 45 years old is $27.8 \%$, whereas the prevalence age for the age group of 60 years old and above is $37 \%{ }^{10}$ All participants in this study are accidentally women, which is concomittant with the epidemiology data that women have a higher risk of developing OA compared to men. ${ }^{7}$

The BMI mean for subjects in this study was $27.34 \mathrm{~kg} / \mathrm{m}^{2}$ with the lowest BMI of 16.01 $\mathrm{kg} / \mathrm{m}^{2}$ and the highest BMI was $37.65 \mathrm{~kg} / \mathrm{m}^{2}$. Most subjects in this study was overweight $(66.67 \%)$. This is consistent with the finding of the previous studies that the majority of knee OA patients are overweight, in which the risk for knee OA is 8.1 times higher than those with normal BMI. $2,5,8$

The quadriceps muscle strength increased significantly after the intervention, which is consistent with findings of previous studies stating that there is an increase in quadriceps muscle strength after the quadriceps muscle strengthening exercises were performed three times a week. ${ }^{9,11}$ Aaboe et al. $^{12}$ also found an increase in quadriceps muscle strength after walking exercise three times a week for twelve weeks. The muscle strength increases through two mechanisms: through changes in peripheral muscles and through adaptations of the nervous system. The major factor contributing to the muscle strength increase is a neural factor occuring in the first two weeks in exercise, while the peripheral muscle change, i.e. muscle hypertrophy, occurs a few weeks after exercise. ${ }^{13}$

Lower extremity lean mass did not increase in this study. This is different from Nilwik et $a .^{14}$ (2013) findings in which the lean mass increase 3\% after the muscle strengthening exercises three times per week for six months with $60-75 \%$ intensity $1 \mathrm{RM}$ among male subjects over 70 years old. This result could be explained by the different duration of study. Nilwik's study was carried out for six months while this study was conducted in only eight weeks.

The correlation between quadriceps muscle strength increase and LELM was found to be insignificant. This is different from findings from previous studies showing an increase in muscle strength along with the lean mass. In these studies, the dose for exercise was 8-12 repetitions per muscle group, with the intensity of $70-85 \% 1 \mathrm{RM}$, three sets every two to three times per week for 8-12 week. ${ }^{15}$

Table Subject Demographics $(\mathrm{N}=36)$

\begin{tabular}{lcc}
\hline & Mean & SD \\
\hline Age & $57.26(51-68)$ & 7.45 \\
Height & $149.86(139-161)$ & 4.65 \\
Weight & $62.57(37-77)$ & 7.49 \\
Body mass index & $27.89(16.01-37.65)$ & 3.52 \\
\hline
\end{tabular}


This study was conducted with the same exercise frequency and duration, but the intensity given was only $60 \%$ of 1 RM. Muscle strengthening exercises with low-moderate intenstity would lead to the recruitment of slow-twitch muscle fibers while increasing the cross-sectional area in small size. The increase in the size of slow-twitch muscle fibers occured in months to years. Muscle resistance exercise require more power because it can make muscle size and recruited muscle fibers increase. Muscle hypertrophy itself is the result of an increase in the size and number of myofibrils in the fast-twitch muscle fibers and slow-twitch. ${ }^{16}$

Muscle strength is determined by various factors, one of them is LELM. This study found that LELM has no correlation with quadriceps strength, which might indicate that LELM plays a small role in increasing muscle strength. A review study suggests that the large variations in muscle strength and cross sectional area are caused by other variables that accounted for differences in strength rather than size alone. ${ }^{17}$ Meanwhile Aagard et $a l^{18}$ found a different result in which the increase in muscle strength after muscle strengthening exercises for six up to nine weeks in elderly subjects $>>60$ years) concomittantly happens with increased muscle strength and also increased diameter of thigh muscles of $10 \%$.

Muscle cross-sectional area is relative to the number and size of muscle fibers. The muscle fibers consist of two types: type 1 and 2. Type 1 fibers or a slow-twitch muscle fibers contract slowly, red coloured, and have oxidative metabolism. Type 2 muscle fibers are fast contracting muscle fibers, white coloured, and contains mostly glycolytic with fewer oxidative enzymes than type 1 . Type 2 responds to a great power in a short time period. ${ }^{13}$ Structural adaptations that occurs in older adults is found to be similar to those of young adults, i.e. adaptation of protein synthesis as well as the contractile elements. This process is started by changes in cell shape leading to mechanical signals that influence gene expression. The protein synthesis then occurs in two stage: posttranslational and translational phases. In posttranslational phase, the messenger RNA (mRNA) myofibrilar protein increases due to increases in the regulation of mRNA by satellite cells. In posttranslasional phase, the satellite cell fused with mature muscle fibers resulting in the synthesis of myonucleus proteins. The satellite cells are also linked to the quantity of genetic and protein needs of muscle fibers in hipertophy phase. The pathway that causes muscle hypertrophy is still unknown but it is thought to be caused by an increase in the number of satellite cells in the muscle, leading to the muscle adaptive response. ${ }^{9}$

Muscle adaptive response only happens in type II muscle fibers. The type II muscle fibers are the ones that experience detrimental loss caused by changes in muscle mass. Atrophy of type II muscle fibers without any reduction in the number of muscle cells is also found in Nilwik's study. ${ }^{13-15}$ A previous study also found the presence of increased LELM after performign the muscle strengthening exercises. These differences are attributed to the fact that the all participants are women in the age range of 46-56 years in this study while the research done by Thomas consists of 30-40 years old male sand females. Women are more likely to have a greater fat mass due to hormonal factors. Lean mass is more in men because testosterone is a major regulator of body composition, particularly the muscle mass. ${ }^{9}$ Women will experience decrease in the production of estrogen that regulates skeletal muscle mass. Estrogen receptor $\alpha$ and $\beta$ are expressed by myoblasts, myotube, and mature muscle fibers. This statement reinforces the hypothesis of the existence of a direct effect of estrogen on the muscles, but the clear relationship regarding the estrogen regulation not yet known. ${ }^{19}$

Muscle strength decreases by $1.5-5 \%$ per year while the leg lean mass only decreases at a rate of $1-2 \%$ annually in individuals who are 50 years old or above. ${ }^{20}$ The LELM value in this study does not experience many changes after muscle strengthening exercises for eight weeks. Another study found that without intervention, the ML will increase $0.45 \mathrm{~kg}$ and the MBL will decrease $0.23 \mathrm{~kg}$ per year. This shows that by doing resistance exercises, the decrease in LM can be prevented. Regular physical activities can prevent the increase of LM in older adults. Fatty infiltration of the muscle can be significantly reduced in subjects with physical activities and weight loss treatment. ${ }^{3,18}$

There are limititations in this study that several variables (i.e. age and menopause) that could affect the LELM are not accounted. It is suggested that the future study should be done in a longer period of intervention, higher exercise intensity and with a control group. 


\section{References}

1. Departemen Kesehatan Republik Indonesia. Riset kesehatan dasar: laporan nasional 2007. Jakarta: Kementrian Kesehatan RI; 2007.

2. Segal N, Glass N, Felson DT, Hurley M, Yang $\mathrm{M}$, Nevitt $\mathrm{M}$, et al. The effect of quadriceps strength and proprioception on risk for knee osteoarthritis. Med Sci Sports Exerc. 2010;42(11):2081-2.

3. Conroy MB, Kwoh CK, Krishnan E, Nevitt MC, Boudreau R, Carbone LD, et al. Muscle strength, mass, and quality in older men and women with knee osteoarthritis. Arthritis Care Res. 2012;64(1):15-21.

4. Petterson SC, Barrance P, Buchanan T, BinderMacleod S, Syder-Mackler L. Mechanisms undlerlying quadriceps weakness in knee osteoarthritis. Med Sci Sports Exerc. 2008;40(3):1-13.

5. Blumenfeld O, Williams F, Hart D, Arden NK, Spector TD, Livshits G. Lower limbs composition and radiographic knee osteoarthritis (RKOA) in Chingford sample-a longitudinal study. Arch Gerontol Geriatr. 2013;56(1):148-54.

6. Sowers MF, Yosef M, Jamadar D, Jacobson J, Karvonen-Gutierres C, Jaffe M. BMI vs. body composition and radiographically defined osteoarthritis of the knee in women: a 4-year follow-up study. Osteoarthr Cartil. 2008;16(3):367-72.

7. Silverwood V, Blagojevic-Bucknall M, Jinks C, Jordan JL, Protheroe J. Current evidence on risk factors for knee osteoarthritis in older adults: a systematic review and meta-analysis. Osteoarthr Cartil. 2015;23(4):507-15.

8. Henriksen M, Christensen R, Danneskiold L, Bliddal H. Changes in lower extremity muscle mass and muscle strength after weight loss in obese patients with knee osteoarthritis: a prospective cohort study. Arthritis Rheum. 2012;64(2):438-42.

9. Thomas MH. Increasing lean mass and strength; a comparison of high frequency strength training to low frequency strength training [desertation]. Missouri: University of Central Missouri; 2011.

10. ZhangY,JordanJ.Epidemiology of osteoarthritis. Clin Geriatr Med. 2010;26(3):355-69.

11. Terzis G, Georgiadis G, Stratakos G, Vogiatzis I, Kavouras S, Manta P, et al. Resistance exercise- induced increase in muscle mass correlates with p70S6 kinase phosphorylation in human subjects. Eur J Appl Physiol. 2008;102(2):14552.

12. Aaboe J, Henriksen M, Bartholdy C, Leonardis $\mathrm{J}$, Rider $\mathrm{P}$, Jorgensen $\mathrm{L}$, et al. The effect of quadriceps strengthening exercise on quadriceps and knee biomechanic during walking in adults with knee osteoarthritis: a randomized controlled trial. Osteoarth. Cartl. 2014;95(22):900-7.

13. Frontera W, Moldover J, Borg-Stein J, Watkins P. Exercise. In: Gonzales E, Myers S, Downey JA, Darling RC, editors. Downey and darling's physiological basis for rehabilitation medicine. Boston: Butterworth Heinemann; 2008. p. 456-88.

14. Nilwik R, Snijders T, Leenders M, Bart B, Kranenburg J, Verdijk B, et al. The decline in skeletal muscle mass with aging is mainly attributed to a reduction in type II muscle fiber size. Exp Gerontol. 2013;48(5):492-8.

15. Mayer F, Scharhag-Rosenberger F, Carlsohn A, Cassel M, Muller S, Scharhag J. The intensity and effects of strength training in the elderly. Dtsch Arztebl Int. 2011;108(21):359-64.

16. Hardman AE, Stensel DJ. Physiologic response and long-term adaptation to exercise. In: Physical activity and health: the evidence explained. $2^{\text {nd }}$ ed. Boston: Routledge; 2009. p.54-6.

17. Jones EJ, Bishop PA, Woods AK, Green JM. Cross-sectional area and muscular strength. Sports Med. 2008;38(12):987-94.

18. Aagard P, Suetta C, Caserotti P, Magnusson $\mathrm{S}$, Kjaer $\mathrm{M}$. Role of the nervous system in sarcopenia and muscle atrophy with strength training as countermeasure. Scand J Med Sci Sports. 2010;20(1):49-64.

19. Svensson J, Moverare-Skrtic S, Windahl S, Swanson C, Sjogren K. Stimulation of both estrogen and androgen receptors maintains skeletal muscle mass in gonadectomized male mice but mainly via different pathways. J Molecular Endocrinol. 2010;45(1):45-7.

20. Keller K, Engelhardt M. Strength and muscle mass loss with aging process. Age and strength loss. Muscle, Ligaments, Tendon J. 2013;3(4):346-50. 